\title{
ROLE OF MULTIDETECTOR COMPUTED TOMOGRAPHY IN EVALUATION OF PARANASAL SINUS PATHOLOGY
}

\section{Radiology}

Anirban Majhi

Bishakha

\section{Shishir Chumber}

\section{Kavita Vani*}

Post Graduate Student, Department Of Radiology, ABVIMS \& Dr. Ram Manohar Lohia Hospital, Delhi.

Post Graduate Student, Department OfAnaesthesia, Hindu Rao Hospital, Delhi.

Research Associate, Department Of Neurology, ABVIMS \& Dr. Ram Manohar Lohia Hospital, Delhi.

Consultant, Department Of Radiology, ABVIMS \& Dr. Ram Manohar Lohia Hospital, Delhi. * Corresponding Author

\section{ABSTRACT}

BACKGROUND: Paranasal sinus diseases are commonly encountered in clinical practice. These include a wide spectrum of pathologies ranging from inflammatory to neoplastic. Clinical examination followed by imaging is the mainstay in making a correct diagnosis. METHODS: 100 consecutive patients underwent CT scan in the department of Radiology using Siemens Somatom Definition Flash 128 slice MDCT scanner as per standard protocol. Images were acquired in the axial plane with reformation in coronal and sagittal planes. RESULTS: Most of the patients were in the age group of 30-39 years. The most common pathology was found to be inflammatory sinonasal disease. The most common CT inflammatory pattern was the osteomeatal pattern. The most common benign tumour was found to be juvenile nasopharyngeal angiofibroma and the most common malignant tumour was squamous cell carcinoma of maxillary sinus. CONCLUSIONS: MDCT proved to be highly sensitive in classifying the lesions into clinically relevant categories, establishing the diagnosis, for delineating the extent and for prognostication. MDCT is the modality of choice for imaging because of its ease, availability, speed and ability to reveal anatomy of structures, commonly found variations, extent of disease process as well as subtle bone changes that are important in diagnosing lesions and most importantly guiding the surgeons to plan the operation.

\section{KEYWORDS}

Computed Tomography, Multidetector Computed Tomography, Paranasal Sinuses, Maxillary Sinus, Ethmoid Sinus, Sphenoid Sinus And Frontal Sinus.

\section{INTRODUCTION}

Paranasal sinus (PNS) diseases are commonly encountered in clinical practice. Clinical examination followed by imaging is the mainstay in making correct diagnosis. Radiological imaging is required to determine the extent of lesion, for pre-operative assessment of sinonasal anatomy and to ascertain the anatomic variations, if any. The utility of plain radiography ${ }^{(1,2)}$ is overshadowed now with improved availability of CT which has far superior spatial resolution. Plain radiography still has a limited role in management of sinusitis, for instance, confirming the presence of air-fluid levels in acute sinusitis as well as in evaluation of size and integrity of the paranasal sinuses ${ }^{(1)}$ However for evaluation of chronic sinusitis where mucosal thickening alone may be present, plain radiography does not suffice. ${ }^{(2)}$ Computed Tomography is an outstanding milestone for imaging of paranasal sinus pathologies. Of the various modalities available, MDCT is preferred for its accuracy, speed, lower cost (as compared with MRI) and ease to work with. It has wide availability and has a user friendly platform. CT scan, with its excellent capability to image both bones and soft tissues reliably, allows higher accuracy of defining the cause and extent of both inflammatory and neoplastic pathologies of PNS. ${ }^{(3)}$ MRI can be done in cases of complications of sinusitis, extrasinus extension of malignancy and to evaluate intracranial extension ${ }^{(4,5)}$. In this study, we aimed to assess the utility of HRCT in sinus disease.

\section{METHODS}

This Institute Ethics Committee approved, cross sectional study was conducted on 100 consecutive patients referred to the Department of Radiodiagnosis with complaints pertaining to nose and paranasal sinuses, such as nasal obstruction, congestion, purulent rhinorrhea, facial pain with or without headache or fever. Detailed history was taken for onset \& duration of symptoms like nasal obstruction, mass, epistaxis, swelling, headache post nasal drip fever etc. History of atopy, allergy and smoking was taken.

All the sinuses (frontal, maxillary, ethmoid \& sphenoid) were assessed for pattern of aeration, location, presence of mucosal thickening, opacification, extent of soft tissue/ bone involvement, expansion of sinuses and anatomical variants.

\section{RESULTS}

Demographic data is as per table 1. Most patients affected by inflammatory sinonasal diseases were less than 40 years of age.

Table 1: Demographic details
\begin{tabular}{|c|c|c|c|}
\hline \multirow{2}{*}{$\begin{array}{c}\text { AGE IN } \\
\text { YEARS }\end{array}$} & \multicolumn{3}{|c|}{ NO OF PATIENTS } \\
\cline { 2 - 4 } & males & Females & TOTAL \\
\hline$<30$ & 23 & 8 & 31 \\
\hline $30-39$ & 24 & 19 & 43 \\
\hline $40-49$ & 10 & 9 & 19 \\
\hline $50-59$ & 3 & 2 & 5 \\
\hline$>60$ & 2 & 0 & 2 \\
\hline TOTAL & 62 & 38 & 100 \\
\hline
\end{tabular}

Table no. 2 lists the number of cases of different pathologies.

Table No 2: Distribution of pathologies

\begin{tabular}{|c|c|c|c|}
\hline Pathology & & & $\begin{array}{l}\text { No of } \\
\text { pt.s }\end{array}$ \\
\hline \multirow[t]{7}{*}{$\begin{array}{l}\text { 1.Inflammatory } \\
\text { sinonasal disease }\end{array}$} & $\begin{array}{l}\text { subacute to } \\
\text { chronic sinusitis }\end{array}$ & Infundibular & 10 \\
\hline & & Osteomeatal & 19 \\
\hline & & Sphenoethmoidal & 5 \\
\hline & & Sinonasal polyposis & 9 \\
\hline & & Sporadic & 7 \\
\hline & \multicolumn{2}{|c|}{ allergic fungal rhinosinusitis } & 10 \\
\hline & \multicolumn{2}{|c|}{ invasive fungal sinusitis } & 2 \\
\hline \multirow{4}{*}{$\begin{array}{l}\text { 2.Benign Non- } \\
\text { inflammatory } \\
\text { Sinonasal Disease }\end{array}$} & \multirow{2}{*}{ Sinonasal polyp } & Ethmoidal polyp & 11 \\
\hline & & AC polyp & 6 \\
\hline & Mucocele & & 5 \\
\hline & Retention cyst & & 2 \\
\hline 3.Tumours and Tumour & Benign & & 7 \\
\hline Like Conditions & malignant & & 2 \\
\hline \multirow[t]{2}{*}{ 4.Miscellaneous } & Rhinolith & & 2 \\
\hline & Osteoma & & 3 \\
\hline \multicolumn{4}{|c|}{ Imaging features of subacute to chronic sinusitis } \\
\hline \begin{tabular}{|l|}
$\begin{array}{l}\text { Mucosal thickening } \\
\text { and opacification }\end{array}$ \\
\end{tabular} & & & 50 \\
\hline $\begin{array}{l}\text { Bone Remodeling } \\
\text { total/ Thinning/ } \\
\text { Sclerosis }\end{array}$ & & & \begin{tabular}{|l|}
$35 / 23$ \\
12
\end{tabular} \\
\hline Air fluid level & & & 8 \\
\hline Anatomical variation & & & 32 \\
\hline $\begin{array}{l}\text { Loco regional } \\
\text { complication. }\end{array}$ & & & 3 \\
\hline
\end{tabular}


Table 3 gives details of anatomical variations found in the subjects and

imaging features of different pathologies.

Table No 3: Anatomical Variations \& Imaging features of various pathologies

\begin{tabular}{|c|c|c|c|c|c|c|}
\hline Type of variation & Agger Nasi cell & Haller cell & Concha Bullosa & $\begin{array}{l}\text { Paradoxical Middle } \\
\text { turbinate }\end{array}$ & \multicolumn{2}{|c|}{ DNS \& Septal spur } \\
\hline No. of cases & 12 & 5 & 6 & 4 & \multicolumn{2}{|l|}{5} \\
\hline $\begin{array}{l}\text { Imaging features of } \\
\text { fungal sinusitis }\end{array}$ & $\begin{array}{l}\text { Bilateral and multi-sinus } \\
\text { involvement(pansinusitis) }\end{array}$ & $\begin{array}{l}\text { Expansion and } \\
\text { thinning of sinus walls }\end{array}$ & $\begin{array}{l}\text { Hyperdensity on plain } \\
\text { scan }\end{array}$ & Calcification & \begin{tabular}{l|} 
Bony \\
Erosion
\end{tabular} & Heterogeneity \\
\hline No. of cases & 7 & 5 & 8 & 3 & 2 & 8 \\
\hline $\begin{array}{l}\text { Imaging features of } \\
\text { Benign Tumors }\end{array}$ & Bone Destruction & Bone Remodeling & Contrast Enhancement & $\begin{array}{l}\text { Invasion of } \\
\text { Surrounding structures }\end{array}$ & \multicolumn{2}{|c|}{ Calcification } \\
\hline No. of cases & 2 & 5 & 5 & 3 & \multicolumn{2}{|l|}{2} \\
\hline $\begin{array}{l}\text { Imaging features of } \\
\text { malignant tumors }\end{array}$ & Bone Destruction & Contrast Enhancement & $\begin{array}{l}\text { Invasion of } \\
\text { Surrounding structures }\end{array}$ & \multicolumn{3}{|l|}{ Calcification } \\
\hline No. of cases & 2 & 2 & 2 & \multicolumn{3}{|l|}{1} \\
\hline
\end{tabular}

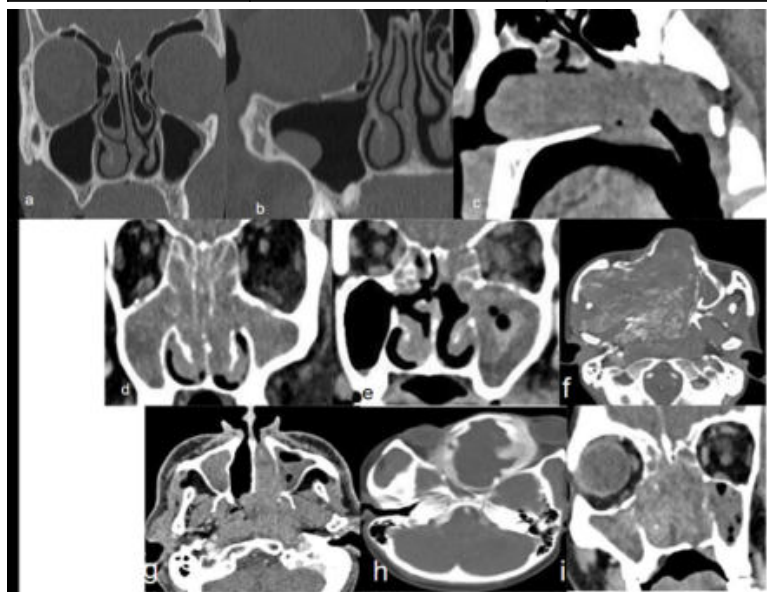

Legend: a. Anatomical variations: DNS and bilateral concha bullosa; b. Mucocele; c. Antrochoanal polyp; d. Chronic sinusitis; e. Fungal sinusitis; $\boldsymbol{f}$. Juvenile nasopharyngeal angiofibroma; $\boldsymbol{g}$. Squamous cell carcinoma; h. Fibrous dysplasia of frontal sinus; $\boldsymbol{i}$. Inverted papilloma.

Tumors and Tumor like conditions were noted in nine patients, of whom, seven were benign (3 JNA, 2 inverted papillomas, 1 hemangioma and 1 fibrous dysplasia ) and two were malignant (both were biopsy proven squamous cell carcinoma). Invasion into the surrounding structures was noted in JNA and inverted papilloma. Calcification was seen in cases of hemangioma and inverted papilloma.

Imaging features of aggressive bone destruction, a hallmark of malignant lesions, was seen in both patients. Contrast enhancement and invasion of surrounding structure were seen in both malignant lesions. Calcification was seen in one case.

Miscellaneous lesions: Three cases were categorized as miscellaneous. Of these, two were rhinoliths and 3 were cases of osteoma

\section{DISCUSSION}

PNS diseases are fairly common in practice and imaging has an important role to diagnose $\&$ to know the extent of disease process. Computed tomography has become the method of choice in evaluation of paranasal sinuses. Radiation exposure, artefacts from metal, such as, dental work etc are the main limitations of paranasal sinus CT. CT is superior to MR in delineating the bony details and anatomical variations. ${ }^{(5,6,7,8)}$ It is vital for planning surgery.

Age distribution: Mean age of patients suffering from sinus disease in the current study was 33.6 years, similar to the study of 2405 patients of chronic sinusitis conducted by Shashy RG et al. ${ }^{(9)}$ where mean age was 39.4 years.

Pattern of involvement: OMC pattern of involvement was seen in most (19/50, that is $38 \%)$ patients of inflammatory sinonasal disease. In the study by Jagram Verma et al. ${ }^{(8)}$ sinonasal polyposis was the commonest ( $41.7 \%$ ) inflammatory sinonasal disease. Babbel et al, ${ }^{(10)}$ noted that, among 500 pts, infundibular (26\%) and OMC types of inflammatory sinonasal disease were the commonest (25\%) types.

Imaging findings: Mucosal thickening was noted in all 50 patients of bacterial sinusitis. Yousem et $\mathrm{al}^{(11)}$ on a study of CT and MRI on 100 patients observed that the positive predictive value of OMC opacification was $79 \%$ for the presence of inflammatory sinonasal disease. The next common finding were mucous cysts. They stated that sclerosis of sinus walls was an important finding that helps in differentiating subacute from chronic sinusitis.

Anatomic variations: Agger nasi cells were most common, while paradoxical middle turbinate was the least common anatomic variation, in the current study. John Earwaker ${ }^{(12)}$ found that concha bullosa was the most common anatomic variant followed by deviated nasal septum (DNS), on MDCT of 800 cases.

Fungal sinusitis: 12 cases had fungal sinusitis, in the current study. Hyper attenuation and heterogeneity of contents, bilateral multi-sinus involvement, multiple areas of bone erosion and thinning were noted in almost all patients of allergic fungal rhinosinusitis (AFRS). Similar observations were made by C.Ekambar Eshwara Reddy et $\mathrm{al}^{(13) .}$. They also noted bilaterality in $58.3 \%$, as against $83.3 \%$ in our study. In our study calcification was noted in $25 \%$ cases; slightly lower than in their study.

Benign non-inflammatory sinonasal disease: In our study 24 patients had non-inflammatory sinonasal disease. On imaging they appeared expansile soft attenuating homogenous masses causing pressure erosion of bones. SH Nanda et al. ${ }^{(14)}$ evaluated 60 patients for nasal polyps. They found that ethmoidal polyps occur far more commonly than antro-choanal polyps by a ratio of $9: 1$

Tumours and tumour like conditions: The most common benign neoplasm was JNA. Mohammed A. Gomaa et $\mathrm{al}^{(15)}$ made a similar observation. The most common malignant pathology was squamous cell carcinoma of maxillary sinus, similar to findings of Azzam MA. Salami et $\mathrm{al}^{(16)}$.

In our study bone destruction and contrast enhancement were noted in both patients of malignant etiology and calcification was seen in 1 case. As per literature, between $80 \%$ and $90 \%$ of all sinonasal tumours are carcinomas and the vast majority of these are either squamous cell or undifferentiated lesions that typically produce aggressive permeative bone destruction seen in up to $80 \%$ cases.

Contrast enhancement and bone remodelling were noted in the majority of benign tumours. Surprisingly, two cases of benign tumours had bony destruction. Calcification was seen in 2 cases - one inverted papilloma and one haemangioma. Our study is in concordance with literature that bony remodelling is a feature of both benign and lowgrade malignant tumours. Focal hyperostosis was also noted in one case of inverted papilloma, similar to the findings of Jeon TY et al. ${ }^{(17)}$ They stated that focal hyperostosis represents an area of tumour origin in $89 \%$ cases.

\section{CONCLUSION}

PNS diseases are commonly encountered in clinical practice. Clinical examination followed by imaging is the mainstay to make the correct diagnosis, to define the extent of the lesion, to demonstrate the assessment of sinonasal anatomy pre-operatively, as well as to ascertain commonly encountered anatomic variations.

MDCT is the modality of choice for imaging because of its availability, speed, high spatial and tissue resolution. 


\section{DECLARATIONS}

Funding: none

Conflict of interest: none declared

Ethical approval: approved by Ethics committee

\section{Abbreviations}

CT: Computed Tomography

MDCT: multidetector CT

PNS: Paranasal sinus

MRI: Magnetic Resonance Imaging

HRCT: High Resolution CT

JNA: Juvenile nasopharyngeal angiofibroma

OMC : Osteomeatal complex

DNS: Deviated nasal septum

AFRS: allergic fungal rhinosinusitis

\section{REFERENCES}

1. Fatterpekar GM, Delman BN, Som PM. Imaging the paranasal sinuses: where we are and where we are going. The Anatomical Record: Advances in Integrative Anatomy and Evolutionary Biology: Advances in Integrative Anatomy and Evolutionary Biology. 2008 Nov;291(11):1564-72

2. Lazar RH, Younis RT, Parvey LS. Comparison of plain radiographs, coronal CT, and intraoperative findings in children with chronic sinusitis. Otolaryngology-Head and Neck Surgery. 1992 Jul;107(1):29-34.

3. Bisdas S, Verink M, Burmeister HP, Stieve M, Becker H. Three-dimensional visualization of the nasal cavity and paranasal sinuses: clinical results of a standardized approach using multislice helical computed tomography. Journal of computer assisted tomography. 2004 Sep 1;28(5):661-9.

4. Zinreich SJ. Rhinosinusitis: radiologic diagnosis. Otolaryngology-Head and Neck Surgery. 1997 Sep;117(3 suppl):S27-34.

5. Hähnel S, Ertl-Wagner B, Tasman AJ, Forsting M, Jansen O. Relative value of MR imaging as compared with $\mathrm{CT}$ in the diagnosis of inflammatory paranasal sinus disease. Radiology. 1999 Jan;210(1):171-6.

6. Kandukuri R, Phatak S. Evaluation of sinonasal diseases by computed tomography. Journal of clinical and diagnostic research: JCDR. 2016 Nov;10(11):TC09.

7. Verma J, Rathaur SK, Mishra S, Mishra AK. The role of diagnostic imaging in evaluation of nasal and paranasal sinus pathologies. International Journal of Otorhinolaryngology and Head and Neck Surgery. 2016 Jul;2(3):140-6.

8. Sonkens JW, Harnsberger HR, Blanch GM, Babbel RW, Hunt S. The impact of screening sinus CT on the planning of functional endoscopic sinus surgery. Otolaryngology—Head and Neck Surgery. 1991 Dec;105(6):802-13.

9. Shashy RG, Moore EJ, Weaver A. Prevalence of the chronic sinusitis diagnosis in Olmsted County, Minnesota. Archives of otolaryngology-head \& neck surgery. 2004 Mar 1;130(3):320-3.

10. Babbel RW, Harnsberger HR, Sonkens J and Hunt S. Recurring Patterns of Inflammatory Sinonasal Disease Demonstrated on Screening Sinus CT. AJNR 13:903912, May/June 1992

11. Yousem DM. Imaging of sinonasal inflammatory disease. Radiology. 1993 Aug;188(2):303-14.

12. Earwaker J. Anatomic variants in sinonasal CT. Radiographics. 1993 Mar;13(2):381415

13. Reddy CE, Gupta AK, Singh P, Mann SB. Imaging of granulomatous and chronic invasive fungal sinusitis: comparison with allergic fungal sinusitis. Otolaryngology invasive fungal sinusitis: comparison with alleric

14. Nanda SH, Bhatia S, Gupta V. Epidemiology of nasal polyps in hilly areas and its risk factors. International Journal of Otorhinolaryngology and Head and Neck Surgery. 2017 Jan;3(1):77-81.

15. Gomaa MA, Hammad MS, Abdelmoghny A, Elsherif AM, Tawfik HM. Magnetic resonance imaging versus computed tomography and different imaging modalities in evaluation of sinonasal neoplasms diagnosed by histopathology. Clinical Medicine Insights: Ear, Nose and Throat. $2013 \mathrm{Jan} ; 6:$ CMENT-S10678.

16. Salami AM. Unilateral Sinonasal Disease: analysis of the clinical, radiological and pathological features. Journal of the Faculty of Medicine. 2009;51(4):372-5.

17. Jeon TY, Kim HJ, Chung SK, Dhong HJ, Kim HY, Yim YJ, Kim ST, Jeon P, Kim KH. Sinonasal inverted papilloma: value of convoluted cerebriform pattern on MR imaging. American Journal of Neuroradiology. 2008 Sep 1;29(8):1556-60. 